\title{
Successful percutaneous balloon occlusion of a large pulmonary arteriovenous malformation
}

\author{
CHRISTOPHER J DUGGAN, VERITY S GRINNELL, PETER C PIGOTT \\ From the Departments of Thoracic Medicine and Radiology, Royal North Shore Hospital, St Leonards, New \\ South Wales, Australia
}

ABSTRACT Percutaneous embolotherapy was carried out successfully in a 79 year old woman with a $56 \%$ shunt through a single pulmonary arteriovenuos malformation.

With appreciable shunting pulmonary arteriovenous malformations produce disabling symptoms; and neurological complications, although less common, may complicate shunts of all sizes. Surgical resection has been the only definitive treatment and where pulmonary arteriovenous malformations are progressive and multiple, as in patients with hereditary haemorrhagic telangiectasia, multiple staged thoracotomies have been necessary. Embolotherapy is now a recognised alternative.

We report a 79 year old patient with a large $(56 \%)$ right to left shunt through a single pulmonary arteriovenous malformation. Closure was effected by means of percutaneous transcatheter balloon embolisation without complications.

\section{Case report}

A 79 year old woman was transferred from a district hospital, where she had presented with dyspnoea, cyanosis, and clubbing. A left lower lobe opacity was first noted on the chest radiograph in 1962, and although it enlarged she remained symptomless until late 1985 . Since then she had developed increasing dyspnoea on exertion and had become bedridden. Clubbing had been present for at least a year and peripheral cyanosis for several months. She had a smoking history of 40 pack years, having stopped eight years previously, but no other relevant history.

Despite central cyanosis there was no respiratory distress at rest. The fingers and toes were clubbed and the conjunctivae plethoric. Examination of the chest showed nothing abnormal and there were no thrills or bruits. The heart rate and blood pressure were normal. Cardiac examination disclosed no abnormalities apart from a grade $2 / 6$ ejection systolic murmur at the base. There were no telangiectases of the skin or mucous membranes and no signs of chronic liver disease.

The chest radiograph showed a single $6 \times 3 \mathrm{~cm}$ rounded opacity behind the heart shadow in the left lung field. The haemoglobin concentration was $17.7 \mathrm{~g} / \mathrm{dl}$. Arterial oxygen tension $\left(\mathrm{PaO}_{2}\right)$ while she was seated was $5.5 \mathrm{kPa}$ in room air

Address for reprint requests: Dr P C Pigott, Department of Thoracic Medicine, Royal North Shore Hospital, St Leonards, NSW 2065, Australia.

Accepted 19 August 1988 and $5.9 \mathrm{kPa}$ with $100 \%$ oxygen. Pulmonary function tests showed mild hyperinflation and airflow obstruction.Intracardiac and pulmonary artery pressures were normaland there was no evidence of an intracardiac shunt. On the basis of the modified Fick equation the calculated right to left 5 pulmonary shunt was $56 \%$.

At pulmonary angiography a solitary pulmonary arteriovenous malformation $(6 \times 5 \mathrm{~cm})$ was identified in the left lower lobe (fig 1). There was a single feeding artery (12 $\mathrm{mm}$ diameter) and venous drainage was by three veins into a left pulmonary vein. Two $15 \mathrm{~mm}$ stainless steel spiders $\overrightarrow{0}$ (Amplatz vascular obstructing device, Cook Inc, Blooming- -0 ton, Indiana) were placed in the feeding artery proximal to the fistula. Two $12 \mathrm{~mm}$ detachable balloons were placedo behind the spiders via a balloon catheter and inflated with contrast medium. The balloons were secured by two Gian-o turco coils placed behind them (fig 2).

When the balloons were inflated the patient was no longer 8 cyanosed. Two days after embolisation she had a $\mathrm{PaO}_{2}$ of $8.7 \overrightarrow{\vec{P}}$ $\mathrm{kPa}$ while seated and breathing room air and $58.5 \mathrm{kPa}$ with $100 \%$ oxygen. By day 3 her haemoglobin concentration had fallen to $13.7 \mathrm{~g} / \mathrm{dl}$.

Symptomatic improvement occurred slowly, presumably owing to the duration of the patient's immobility. By two months she had a good exercise tolerance and her $\mathrm{PaO}_{2}$ was $10.8 \mathrm{kPa}$ while she was breathing room air.

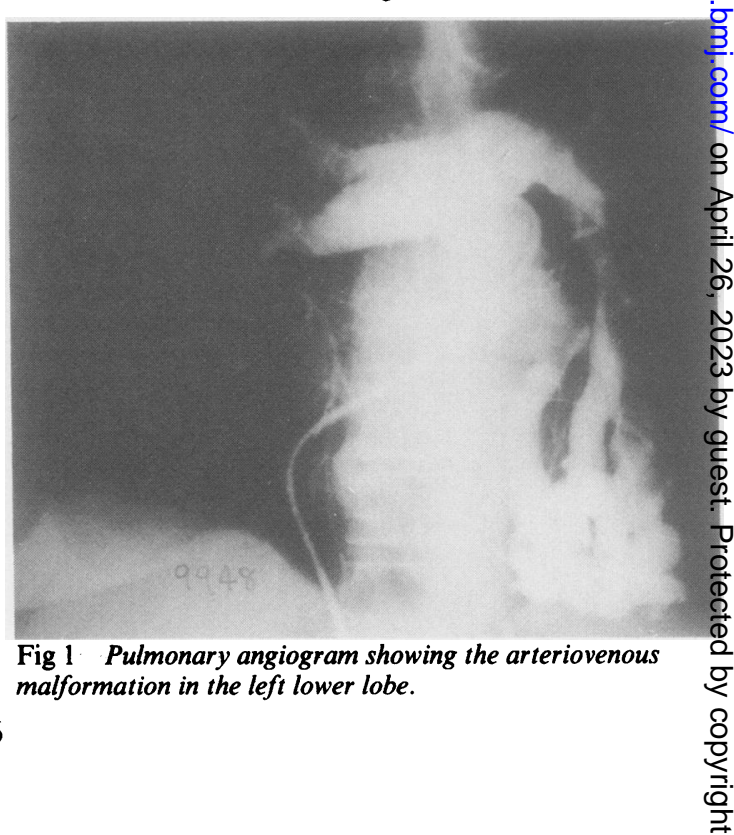




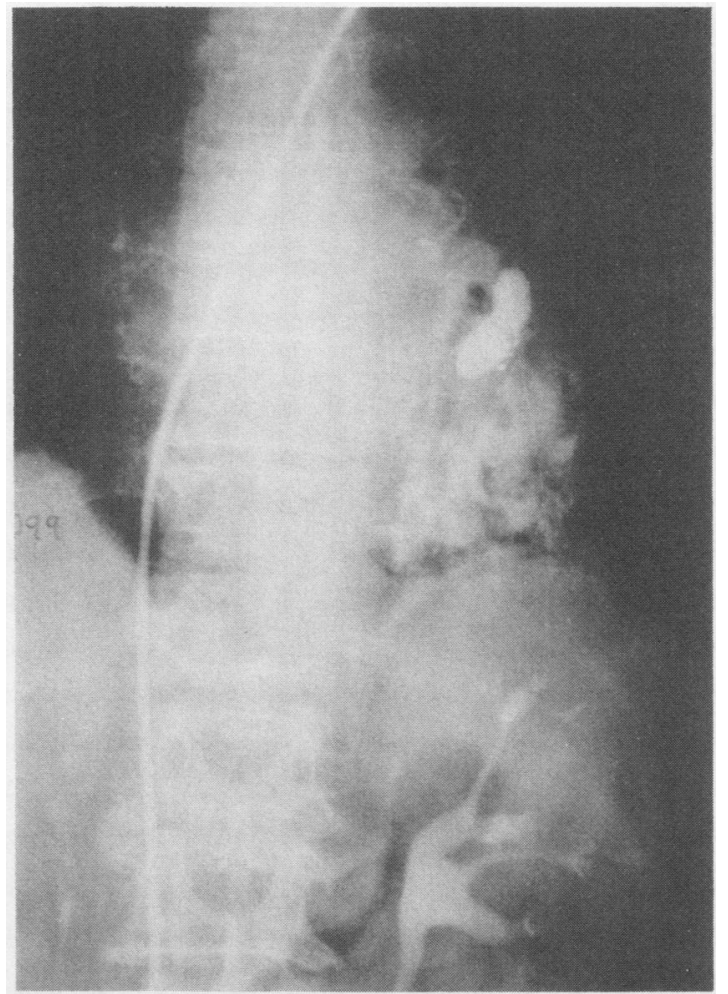

Fig 2 Late post-angiogram radiograph after embolisation. One coil is seen between the balloons and the other is behind and obscured by the upper balloon. The tip of one spider is seen below the lower balloon.

\section{Discussion}

Percutaneous transcatheter embolotherapy was successful in this patient with a solitary large pulmonary arteriovenous malformation. Ths risks of the procedure were considered to be acceptable and less than the risks of surgery.

Embolotherapy has been widely used in the management of congenital and acquired systemic arteriovenous malformations and in the control of haemorrhage. The first successful occlusion of a pulmonary arteriovenous malformation by embolotherapy was in 1978 and used steel coils.' Since 1980 detachable, inflatable balloons have been used to occlude large malformations in patients with multiple pulmonary arteriovenous malformations. ${ }^{2-5}$ Our patient was older than previous patients, had a solitary malformation, no evidence of hereditary haemorrhagic telangiectasia, and a larger shunt.

Details of the technique have appeared previously. ${ }^{3}$ Our modification was the initial placement of two $15 \mathrm{~mm}$ spiders because our largest available embolus (a detachable balloon with an estimated inflated diameter less than $1 \mathrm{~cm}$ ) was smaller than the lumen of the feeding vessel. After two maximally inflated balloons were detached in the feeding artery, test injections showed residual flow and movement of the balloons within the artery. Two coils were therefore placed proximal to the balloons to wedge them and promote clotting. Complications with this technique are uncommon and generally minor, ${ }^{35}$ and the major one, antegrade or retrograde migration of the embolus, ${ }^{67}$ can be prevented by placement of coils and spiders as in our case.

Embolotherapy avoids major surgery and general anaesthesia, preserves functioning lung parenchyma, and can be repeated in patients with recurrent, progressive, or multiple malformations. It appears to be curative for pulmonary arteriovenous malformations unlike systmic malformations, which may recur after initial embolisation. ${ }^{3}$

The raised haemoglobin concentration commonly seen with large shunts is generally assumed to be caused by an increased red cell mass due to arterial desaturation, though only one study of pulmonary arteriovenous malformation has documented this. ${ }^{8}$ Red cell mass and plasma volume were not measured in our patient, but the rapid fall in haemoglobin concentration suggests that the high value may have been due to plasma volume contraction rather than increased red cell mass.

Recent reviews have highlighted the need to consider embolotherapy for virtually all pulmonary arteriovenous malformations, ${ }^{910}$ though no consensus on management has been reached. Non-intervention carries a well recognised risk of morbidity and mortality,' as the lesions enlarge as in our patient and allow systemic or paradoxical embolisms to develop. Surgery for discrete lesions has been associated with lower morbidity and mortality than a conservative approach. ${ }^{9}$ Although experience is limited, embolotherapy appears to be effective, with little associated morbidity, ${ }^{36}$ even in frail, elderly patients and those with large malformations. A conservative approach is probably justified only for diffuse pulmonary telangiectasia-and here lung transplantation may be an alternative. ${ }^{9}$

We thank Dr K R Burgess (Manly District Hospital), who made the clinical diagnosis and referred the patient to us. Miss B Jones and Angela Mansfield provided expert secretarial assistance.

\section{References}

1 Taylor BG, Cockerill EM, Manfredi F, Klatte EC. Therapeutic embolisation of the pulmonary artery in pulmonary arteriovenous fistula. Am J Med 1978;64:360-5.

2 Terry PB, Barth KH, Kaufman SL, White RI. Balloon embolization for treatment of pulmonary arteriovenous fistulas. $N$ Engl J Med 1980;302:1189-90.

3 White RI, Mitchell SE, Barth KH. Angioarchitecture of pulmonary arteriovenous malformations: an important consideration before embolotherapy. AJR 1983;140:681-6.

4 Rankin RN, McKenzie FN, Ahmad D. Embolization of arteriovenous fistulas and aneurysms with detachable balloons. Can J Surg 1983;26:317-20.

5 Kumar S, Ruttley MJ, Fisher DJ. Bilateral pulmonary arteriovenous fistulae treated with balloon embolization. Postgrad Med J 1986;62:209-11.

6 Barth HK, White RI, Kaufman SL, Terry PB, Roland JM. Embolotherapy of Pulmonary Arteriovenous malformations with detachable balloons. Radiology 1982;142:599-606.

7 Hatfield DR, Fried AM. Therapeutic embolization of diffuse pulmonary arteriovenous malformations. AJR 1981;137: 861-3.

8 Moyer JH, Glantz G, Brest AN. Pulmonary arteriovenous fistulas. Am J Med 1962;32:417-35.

9 Burke CM, Safai C, Nelson DP, Raffin TA. Pulmonary arteriovenous malformations: A critical update. Am Rev Respir Dis 1986;134:334-9.

10 Flower CDR. Imaging pulmonary arteriovenous malformations. Br Med J 1987;294:1633-4. 